\title{
Instrumental records received in 11 storey steel frame building during a remote earthquake
}

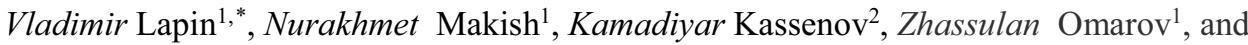 \\ Dauren Kassenov ${ }^{1}$ \\ ${ }^{1}$ JSC "Kazakh Research and Design Institute of Construction and Architecture", Almaty, 21 \\ Solodovnikova, Kazakhstan \\ ${ }^{2}$ Satbayev University, 050013,Almaty, 22a Satbayev st,,Kazakhstan
}

\begin{abstract}
On August 9, 2017, a strong earthquake with a magnitude $\mathrm{M}_{\mathrm{w}}$ $=6.3$ occurred in the Xinjiang Uygur Autonomous Region of China. For the first time in the last 10 years, representative instrumental data were obtained at the seismic station No. 11 ("Prospect Abay") in the city of Almaty, equipped with a digital instrumentation and measuring system. The building is eleven-story and is made in a steel frame. In the city of Almaty, there is a significant number of residential and public buildings made in a steel frame. Using the AT 1105 sensors and the RSM- 8 recorder, high-quality instrumental records of accelerations in the basement and on the roof of the building were obtained, as well as the $\beta$ spectral curves. The frequency composition of the impact at the basement level has been determined. The prevailing period of fluctuation at the basement level is $0.3 \mathrm{sec}$, and at the roof level is close to $1.3 \mathrm{sec}$. It was found that during a remote earthquake, resonant vibrations of the building took place. The results of the work can be used in the design of buildings with a steel frame in the city of Almaty.
\end{abstract}

\section{Introduction}

The seismic hazard of the city of Almaty is usually associated with the seismically active zones of the Northern Tien Shan. The areas of the Trans-Ili and Kungey Alatau ridges are especially highly seismic. There are the main seismogenic zones located close to the city - Almaty, Trans-Ili and Chiliko-Kemin. Their seismic potential is very high - the possible magnitudes of the strongest earthquakes with sources in these zones are, respectively, from 7.5 to 8.5 , and the intensity of earthquakes in the city can reach from 8 to 10 points [1-4].

The city was destroyed twice by strong earthquakes - Vernenskoye in 1887 with a magnitude of 7.2 and Keminskoye, in 1911 with a magnitude of 8.2. Moreover, the last earthquake had a class of seismic disasters and was felt over an area of 2 million square kilometers. The city has repeatedly experienced less severe earthquakes. The ZhalanashTyup earthquake of 1978 with a magnitude of 6.9, the Suusamyr earthquake of 1992 with a

*Corresponding author: lapin_1956@list.ru 
magnitude of 7.3, the Baisorun earthquake of $1990, \mathrm{M}=6.3$ can be noted. On the territory of the city, they were felt with an intensity of 5-6 points [3].

For a long time, there was a firm conviction that there were no earthquake foci on the territory of the city. It was believed that faults located on the territory of the city could enhance or weaken the effect of the passing seismic waves of earthquakes with foci in other seismogenic zones outside the city.

In the last 15 years, the emergence of earthquake foci was noted in the city, the magnitude of which was noted within 2-3.

In the city of Almaty, there are 10 engineering seismometric stations placed on buildings, which also recorded earthquakes with foci in the city. The stations are equipped with digital and analogue systems. It is planned to modernize the network of stations using modern measuring systems [4-9].

The purpose of the study is to obtain information on the spectral characteristics of ground vibrations, as well as the dynamic characteristics of the building, based on the analysis of instrumental records of the earthquake.

\section{Method and subject of research}

The analysis of instrumental records of various earthquakes, obtained by the engineering and seismometric service of Kazakh Scientific Research and Design Institute of Civil Engineering and Architecture, using digital and analog accelerometers, continues.

According to the operational data of the Data Center of the RSE IGI, on August 9, 2017 at 05:27 am Astana time (August 8 at 11:27 pm GMT) in the border region of China and Kazakhstan, $100 \mathrm{~km}$ from the Dostyk settlement, $360 \mathrm{~km}$ from the city of Taldykorgan, 480 $\mathrm{km}$ from the city of Almaty, an earthquake occurred. Epicenter coordinates: 44.44 degrees north latitude, 82.92 degrees east longitude. Magnitude $\mathrm{M}_{\mathrm{w}}=6.3$. The earthquake was felt in Almaty and was 4 points in Taldykorgan.

The depth of the earthquake source, according to various sources, is $15-30 \mathrm{~km}$.

This is the strongest recorded earthquake in Almaty in 2017. It should be noted that for the city of Almaty, earthquakes with foci near and even in the city are more typical.

The earthquake was recorded by almost all stations of the engineering and seismometric service of Kazakh Scientific Research and Design Institute of Civil Engineering and Architecture. Instrumental recordings of the earthquake turned out to be very interesting.

Station No. 11 "Prospect Abay" is located on an 11-storey office building made in a metal frame (Fig. 1). It should be noted that this station is one of the very first ones in Almaty and has been operating since 1970. In 2010, the first modernization of the station took place - a digital instrument-measuring system was installed. 


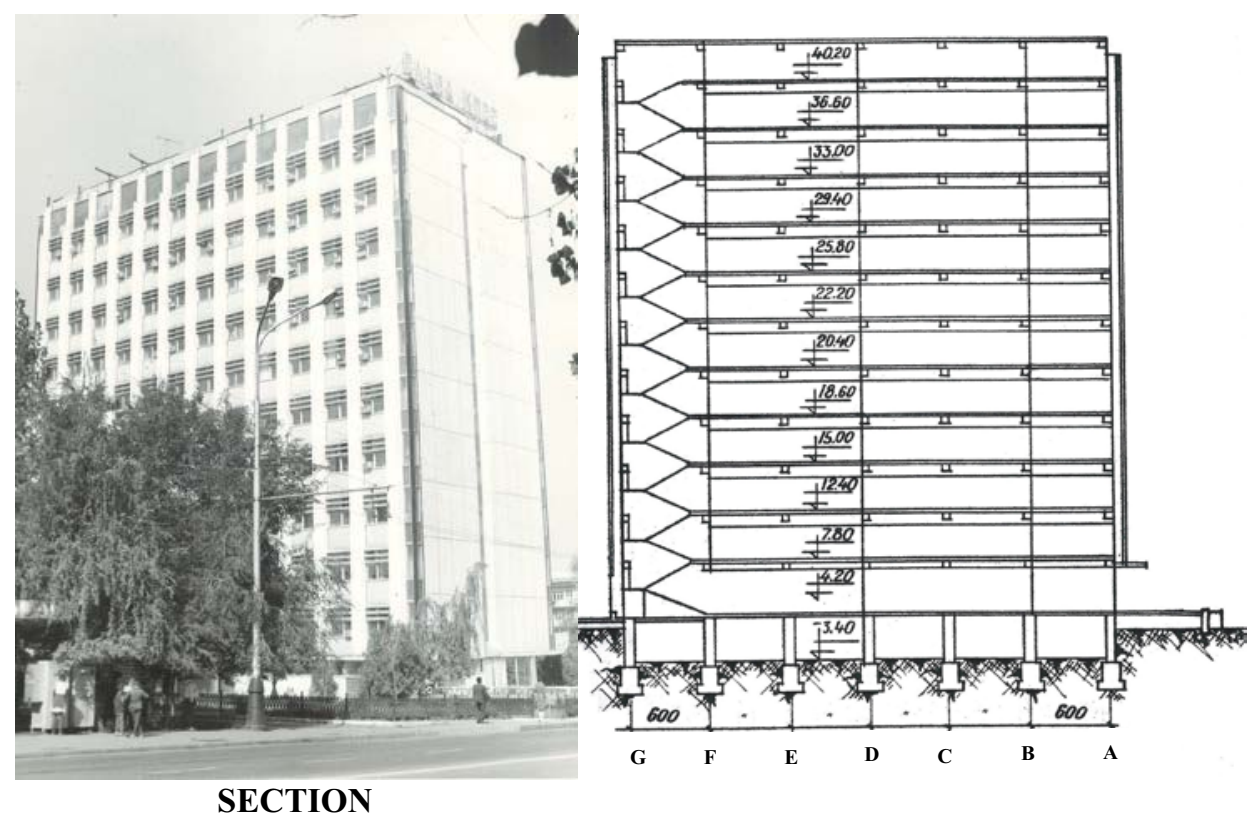

Fig. 1. View and vertical section of the building.

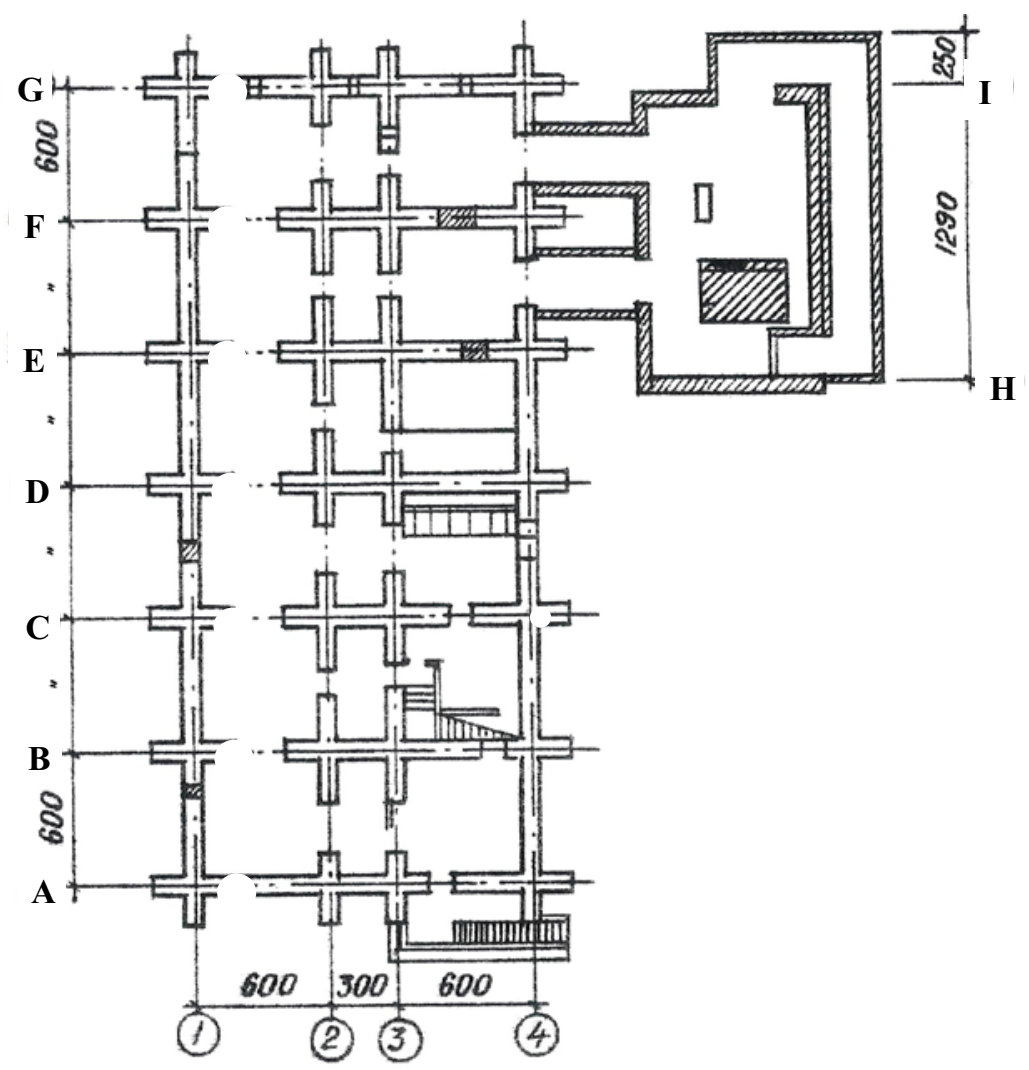

Fig. 2. Section in the horizontal plane. 
The second upgrade was carried out in 2016: the ADXL accelerometers were replaced by the AT 1105 .

The soils are boulders.

The building has dimensions of $15 \times 36 \mathrm{~m}$, height $43.6 \mathrm{~m}$.

From a constructive point of view, the building is frame-panel. External wall panels made of aluminum with glass and stemolite filling.

The frame consists of longitudinal and transverse closed frames with a transverse and longitudinal column pitch of $6 \mathrm{~m}$. The height of the basement is $3.4 \mathrm{~m}$, the first floor is 4.2 $\mathrm{m}$ and all subsequent ones are $3.6 \mathrm{~m}$.

Concrete tape foundations. The basement walls are made of monolithic concrete. The columns of the frame are anchored to the walls of the basement with the help of metal shoes.

Ceilings over the first and basement floors are made of monolithic reinforced concrete; over the rest of the floors, the ceilings are made of prefabricated reinforced concrete ribbed slabs of $3-6 \mathrm{~m}$ in size.

The partitions are made of prefabricated expanded clay concrete panels, as well as from precast gypsum concrete and slag concrete slabs.

At the top of the building there is a technical floor (12th floor), where part of the control and measuring equipment is located - the upper registration point (mark $40.2 \mathrm{~m}$ ). The lowest registration point is located in the basement (Fig. 1). The devices are located at an elevation of $-4.4 \mathrm{~m}$ (the basement itself is at an elevation of $-3.4 \mathrm{~m}$ ). Figure 2 shows a section of the building in the horizontal plane.

Station 11 is equipped with an RSM-8 recorder installed in standby mode. This is the first domestic 8-channel digital system of this type.

In 2016, ADXL sensors at station No. 1 "Institute" were replaced by AT 1105 sensors of Russian production. This made it possible to record even rather weak seismic events.

Thus, the research methods are experimental - the instrumental records of the engineering-seismometric service station installed in the standby mode are analyzed.

\section{Results}

Table 1 shows the maximum values of accelerations for each of the components of instrumental recordings, effective durations, values of the spectral coefficient, values of the period of the maximum of the spectrum. Lines 4-6 correspond to the basement of the building, 1-3 - roofs. The distribution of acceleration over the height of the building shows that the building is deformed in accordance with the first mode of vibration.

Table 1. Maximum values of accelerations and parameters of accelerograms.

\begin{tabular}{|c|c|c|c|c|c|}
\hline № & Component & $\begin{array}{c}\text { Acceleration, } \\
\mathbf{c m} / \mathbf{s}^{\mathbf{2}}\end{array}$ & $\begin{array}{c}\text { Effective } \\
\text { duration, sec }\end{array}$ & $\begin{array}{c}\text { Spectral } \\
\text { coefficient }\end{array}$ & $\begin{array}{c}\text { Spectrum maximum } \\
\text { period, sec }\end{array}$ \\
\hline 1 & $96-11-0-\mathrm{u} 1-\mathrm{OX}$ & 14.31 & 42.75 & $5.33(3.43)$ & $0.42(1.15)$ \\
\hline 2 & $96-11-0-\mathrm{u} 2-\mathrm{OY}$ & 14.52 & 52.86 & $4.67(4.60)$ & $1.29(0.40)$ \\
\hline 3 & $96-11-0-\mathrm{u} 3-\mathrm{OZ}$ & 5.41 & 65.66 & 6.07 & 0.16 \\
\hline 4 & $96-11-0-\mathrm{u} 6-\mathrm{OX}$ & 4.82 & 29.96 & 4.13 & 0.29 \\
\hline 5 & $96-11-0-\mathrm{u} 7-\mathrm{OY}$ & 5.64 & 35.26 & 4.67 & 0.30 \\
\hline 6 & $96-11-0-\mathrm{u} 8-\mathrm{OZ}$ & 2.33 & 42.99 & 4.13 & 0.28 \\
\hline
\end{tabular}


The spectral curves were determined by integrating the differential equation of the classical one-mass oscillator using the standard solvers of the MATLAB computer mathematics system. The functions were used to solve stiff problems by the implicit trapezoidal method or the implicit Runge-Kutta method. Accelerogram sampling step $0.0064 \mathrm{~s}$. The decrement of fluctuations in determining the spectral curves is taken equal to $5 \%$ of the critical value.

Figures 3-4 show accelerograms at the basement and roof level along three orthogonal axes. Accelerations are measured in $\mathrm{m} / \mathrm{s} 2$.

According to the amplitudes of accelerations in the basement level, the intensity of the ground shaking in the area of the seismic station is approximately three-point. Accelerations in the horizontal plane, both in the basement level and in the roof, are quite close.

Figure 5-6 shows the spectral curves at the basement and roof levels.

According to the spectral composition at the basement level along the OX axis, the prevailing period is within $0.29 \mathrm{sec}$. On the OY axis, the impact is high frequency with a period of $0.3 \mathrm{sec}$. Taking into account that the accelerometers are located at an elevation of $-4.4 \mathrm{~m}$ in the pit in the basement of the building, it should be noted that this is apparently the predominant period of vibration of the foundation soil (boulder).

At the roof level, the frequency composition is quite complex. The spectral curves in the horizontal plane are double humped. Apparently, the period of natural vibrations of the steel frame along both axes is within 1.15-1.29 sec. The spectra are quite broadband and very rugged. This is apparently determined by the significant magnitude of a distant earthquake with a magnitude of $\mathrm{M}_{\mathrm{w}}=6.3$.

On the vertical axis, the prevailing periods of fluctuations are $0.16-0.28 \mathrm{sec}$, increasing towards the last floor.

The values of the spectral coefficient at the basement level are approximately the same.

It should be noted a significant effective duration from $30 \mathrm{sec}$ to $65 \mathrm{sec}$ (table 1). Here, the effective duration is the duration of oscillations with an amplitude of at least half the maximum. 

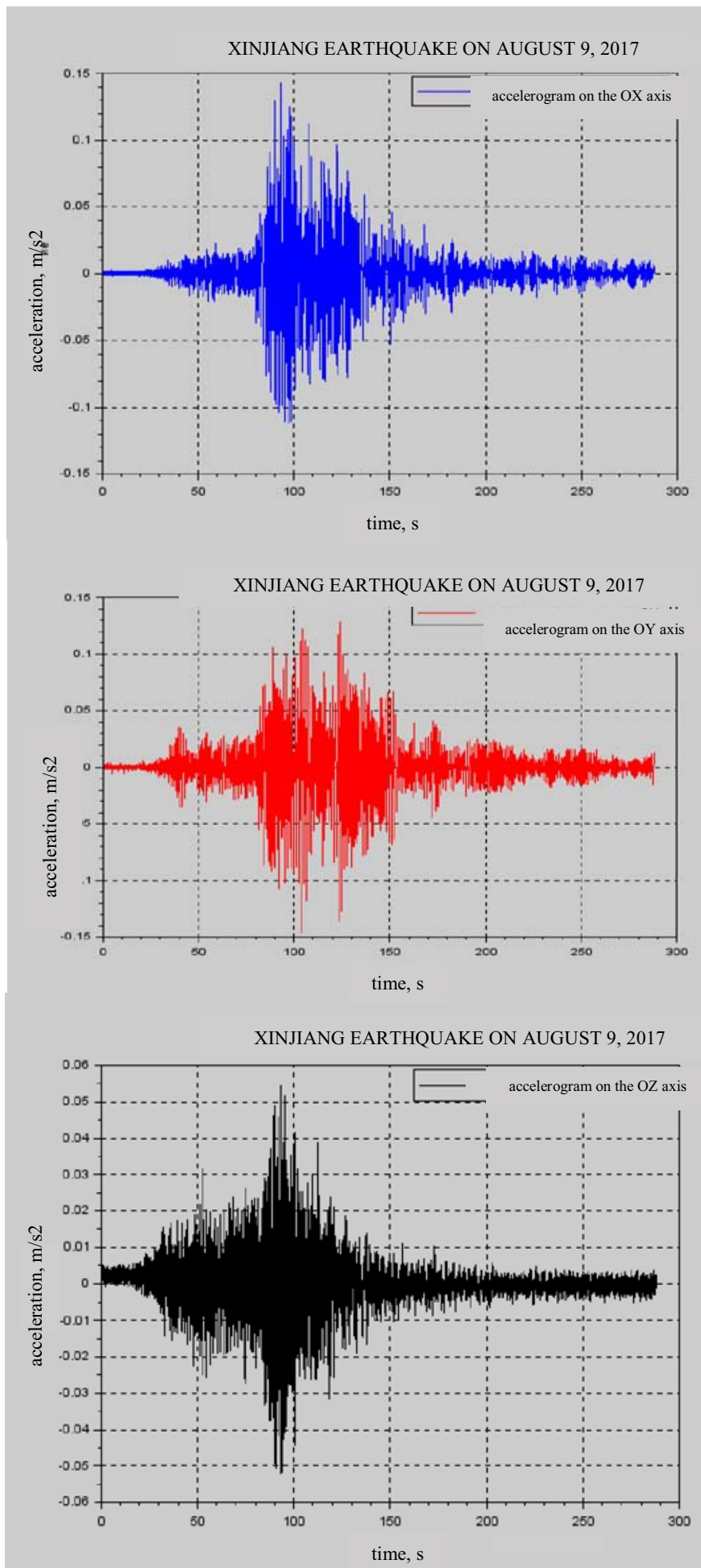

Fig. 3. Accelerograms of the earthquake of 08/09/2017 (station No. 11 "Prospect Abai", roof). 

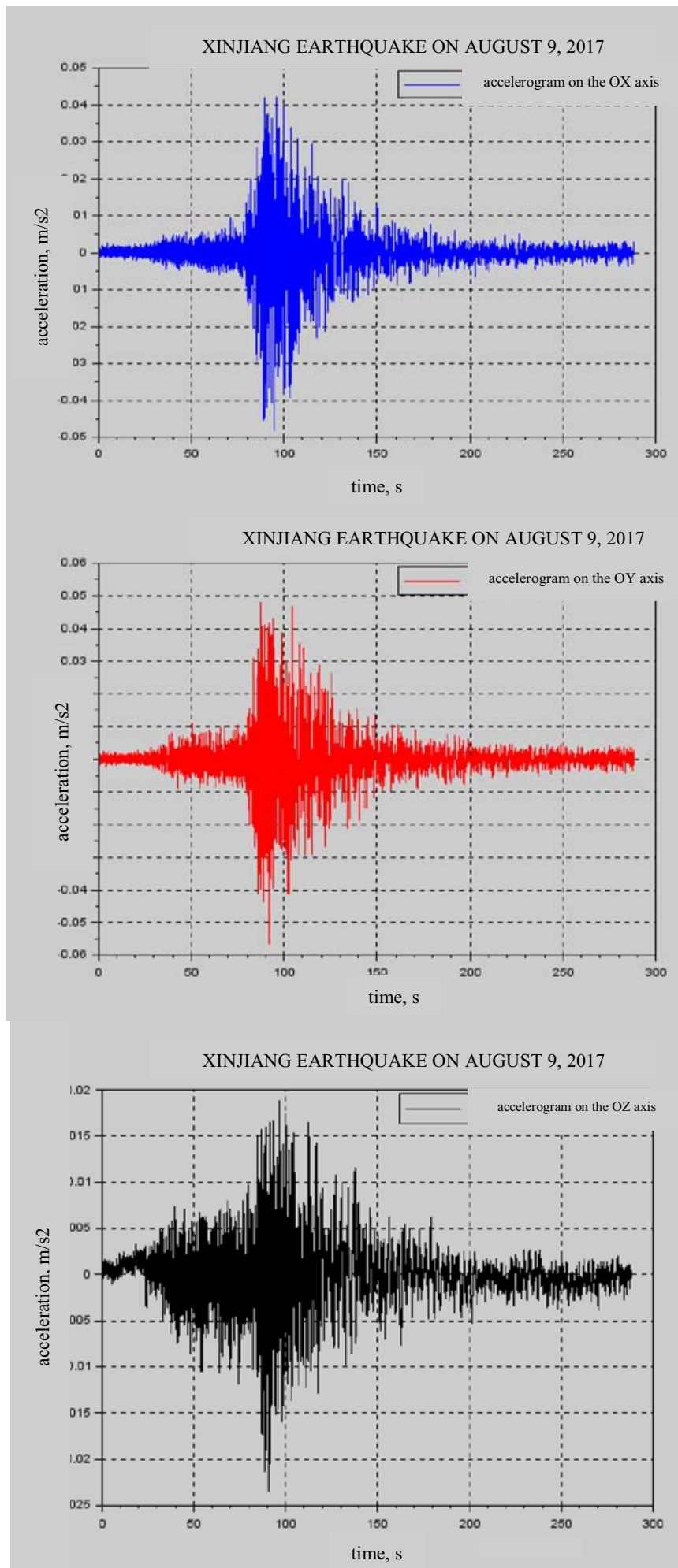

Fig. 4. Accelerograms of the earthquake of 08/09/2017 (station No. 1 "Prospect Abay", basement). 


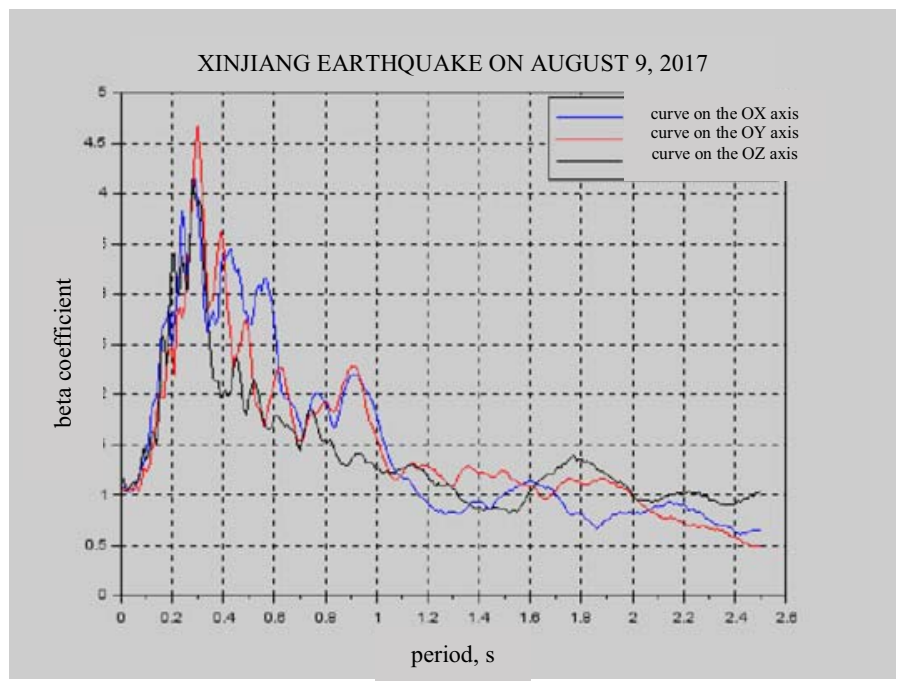

Fig. 5. Spectral curves seismic events 08/09/2017 (basement).

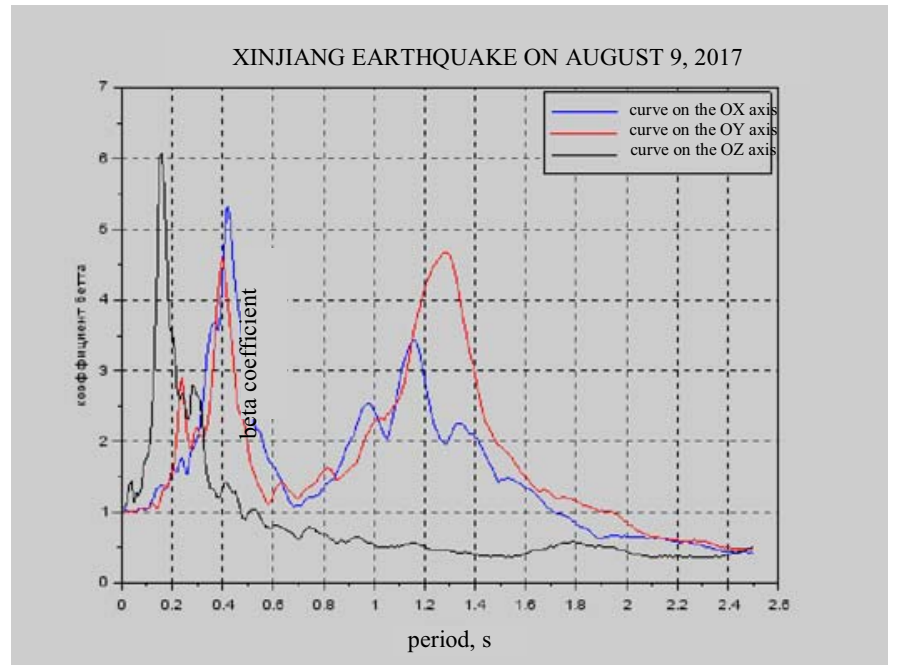

Fig. 6. Spectral curves seismic events $08 / 09 / 2017$ (roof).

\section{The discussion of the results}

Dozens of steel-framed civil and administrative buildings have been built in the city of Almaty. These are buildings with a height of 10 to 18 floors. Therefore, it is very important to study the behavior of such buildings in a real earthquake. Unfortunately, only one building has an engineering and seismometric service station installed on buildings.

According to the results of the analysis of the accelerograms of the remote earthquake of August 9, 2017, the oscillation period of an 11-storey building with a steel frame of 1.29 - $1.30 \mathrm{sec}$ can be considered established. It can be predicted that buildings with a height of up to 18 floors will have an oscillation period of presumably up to 1.5 seconds.

It should also be noted that this 11-storey building is located between two tectonic faults, the distance to which is from $700 \mathrm{~m}$ to $900 \mathrm{~m}$. Therefore, the building is a very 
important object for observation, as it will allow to assess the influence of tectonic faults on the deformativity of the building.

An important result is the establishment of the fact of resonant vibrations of the building during remote earthquakes. It should be noted that high-frequency vibrations of the foundation soil are predicted for earthquakes near the city of Almaty.

Thus, even a weak but tangible earthquake delivers information about both the dynamic characteristics of the building and the spectral characteristics of ground motion.

It is necessary to continue the installation of engineering and seismometric service stations on high-rise buildings, on buildings with new constructive solutions, including objects with various seismic isolation systems [10-15] and buildings with pile foundations [17].

\section{Conclusion}

1. Seismic event (earthquake in Xinjiang Uygur Autonomous Region, China) on August 9, 2017 on the territory of Almaty in the area of seismic station No. 11 "Prospect Abai" is an earthquake with an intensity of at least 3 points (3-4 points). Accelerations in the horizontal plane at the roof level are approximately equal to the same values during the earthquake of August 16, 2014 [16].

2. Acceleration in the horizontal plane at the basement level is practically the same. The period of the spectrum maximum characterizes the frequency characteristics of the foundation soil and has a value of $0.3 \mathrm{sec}$.

3. Accelerations in the horizontal plane are 3-4 times less than during the 5-6 point Zhalanashtyup earthquake on March 25, 1978, recorded at the same station.

4. At the level of the roof on the horizontal plane, spectral curves with two maxima.

5. The digital instrumentation and measuring system RSM-8 with AT 1105 accelerometers is an effective means of registering earthquakes. Seismic station No. 11 "Prospect Abai" is in working order.

6. Accelerometers AT 1105 should be used in the modernization of digital instrumentation and measuring systems of the network of ISS stations of KazRDICA JSC.

\section{Acknowledgements}

The research was carried out using the funds of the grant AP 05130702 of the Ministry of Education and Science of the Republic of Kazakhstan.

\section{References}

1. N.N. Mikhaylova, I.N. Sokolova, A.E. Velikanov, A.N. Sokolov, Bulletin of the National Nuclear Center 3, 87-93 (2015)

2. N.N. Mikhailova, A.N. Uzbekov, News of the national academy of sciences of the republic of Kazakhstan. Series of geology and technical sciences 3(429), 146-155 (2018) ISSN 2518-170X, http://www.geolog-technical.kz/images/pdf/g20183/146155.pdf

3. R.M. Galperin, I.L. Nersesov, E.I. Galperin, Seismic regime of Almaty for 1972-1982 years (Science, Moscow, 1985)

4. A.B. Sadykova, N.V. Silacheva, N.P. Stepanenko, Series of geology and technical sciences 1(445), 127-134 (2021) https://doi.org/10.32014/2021.2518-170X.18 
5. M. Deng, M. Wang, S. Jin, Q. Zhang, K. Chen, S.A. Cheng, Geoscientific Instrumentation Methods and Data Systems 8, 13-19 (2019) https://doi.org/10.5194/gi8-13-2019

6. X. Zhang, Q. Zhang, M. Wang, et al., Geoscientific Instrumentation Methods and Data Systems 6, 495-503 (2017) https://doi.org/10.5194/gi-6-495-2017

7. L. Yang, L. Stehly, A. Paul, Geophysical Journal International 214(2), 1136-1150 (2018) https://doi.org/10.1093/gji/ggy188

8. S. Qiao, H. Duan, Q. Zhang et al., Geoscientific Instrumentation Methods and Data Systems 7, 253-263 (2018) https://doi.org/10.5194/gi-7-253-2018

9. L. Groukamp, J.J. Rossow, C.J.S. Fourie, L. Cormbrinck, African Journal of Geology 114(3/4), 573-576 (2011) https://doi.org/10.2113/ gssajg.114.3-4.573

10. A.F. Bulat, V.I. Dyrda, M.I. Lysytsya, S.M. Grebenyuk, Strength of Materials 50(3), 387-395 (2018) http://doi.org/10.1007/s11223-018-9982-9

11. S. Ahmad, F. Ghani, A. Md Raghib, Construction \& Building Materials 23, 146-152 (2009) https://doi.org/10.1016/j.conbuildmat.2008.01.012

12. V. I. Dyrda, A. Kobets, A.F. Bulat, et al., E3S Web of conference 168, 00042 (2020) https://doi.org/10.1051/e3sconf/202016800042

13. V. Lapin, 16th World Conference on Seismic Isolation, Energy Dissipation on Active Vibration Conference of Structures. 2020, p.325-332. http://doi.org/10.13753./26867974-2019-16-482-527

14. A.F. Bulat, V.I. Dyrda, S.N. Grebenyuk, M.I. Klimenko, Strength of Materials 51(2), 183-192 (2019) https://doi.org/10.1007/s11223-019-00064-x

15. S. Yerzhanov, 16th World Conference on Seismic Isolation, Energy Dissipation on Active Vibration Conference of Structures, 955-963 (2020) http://doi.org/10.13753./2686-7974-2019-16-919-927

16. S.Y. Yerzhanov, V.P. Daugavet, V.A. Lapin, The collection "Researches of earthquake resistance of building and construction" 23(33), 145-163 (2015)

17. A.Zh. Zhussupbekov, J. Frankovská, J. Stacho, et al., 15th Asian Regional Conference on Soil Mechanics and Geotechnical Engineering, ARC 2015: New Innovations and Sustainability, 2704-2709 (2015)_https://doi.org/10.3208/jgssp.TC305-05 